\title{
OtimizaÇÃo da UTilizaÇÃo de Marcadores Moleculares microssatélites e sua Aplicação em estudos com Plantas DANINHAS ${ }^{1}$
}

\author{
Optimization of the Use of Micro-satellite Molecular Markers in Weed Science Studies
}

\author{
GOULART, I.C.G.R. ${ }^{2}$, MEROTTO JUNIOR, A. ${ }^{3}$, NUNES, A.L. ${ }^{4}$ e BERED, F. ${ }^{5}$
}

\begin{abstract}
RESUMO - Apesar de existirem marcadores moleculares mais especificos, os marcadores microssatélites apresentam grande potencialidade de utilização na área de plantas daninhas devido à sua crescente disponibilização em outras espécies e à qualidade das informações proporcionadas. O uso convencional dos marcadores moleculares microssatélites demanda grande quantidade de trabalho e recursos financeiros. O objetivo deste trabalho foi descrever a técnica da cauda fluorescente como forma de otimização da utilização de marcadores moleculares microssatélites, utilizando como exemplo um estudo de identificação de híbridos entre arroz-vermelho e cultivado. Foram utilizadas como modelo plantas de arroz cultivado, arroz-vermelho e o híbrido originado do cruzamento artificial dessas plantas. A técnica da cauda fluorescente consiste na sintese do iniciador forward com a sequência desejada e a adição da sequência de um iniciador universal, que corresponde à chamada cauda. A detecção da amplificação é realizada em equipamento de eletroforese capilar automatizada, através da utilização de um iniciador universal sintetizado com fluoróforo. O sistema desenvolvido foi eficiente na identificação da hibridização entre arroz cultivado e vermelho e apresenta viabilidade de utilização, por exemplo, em estudos de fluxo gênico da resistência a herbicidas e de caracteres relacionados à adaptação diferencial entre essas plantas. A técnica da cauda fluorescente possibilitou o uso de diversos marcadores moleculares a partir de um único marcador fluorescente e viabilizou a realização das análises em multiplex. O aumento da disponibilidade e do conhecimento de técnicas moleculares pode proporcionar melhor elucidação em vários estudos relacionados a espécies de plantas daninhas que possuem pouca disponibilidade de marcadores moleculares especificos.
\end{abstract}

Palavras-chave: arroz-vermelho, cauda M13, hibridização, primer marcado, simple sequence repeats, SSR.

\begin{abstract}
Although more specific molecular markers have been developed, micro-satellite markers have a great potential to be used in weed science, because of their increasing availability to other species and quality of the information provided. The conventional use of micro-satellite molecular markers is laborious and expensive. The objective of this study was to describe the M13 tailed primer method for the optimization of the use of micro-satellite molecular markers, using as example, a study of hybrid identification between cultivated rice and red rice. Cultivated rice and red rice plants, as well as a hybrid originated from the artificial crossing of these plants were used as model. The M13 tailed primer method consists in the synthesis of the forward primer with the desired sequence and the addition of the sequence of a universal primer which corresponds to the tail. Amplification detection is performed on automated capillary electrophoresis equipment by using a labeled universal primer in the PCR. The system developed was effective in identifying the hybridization between the cultivated rice and red rice and it was useful, for example, in studies of
\end{abstract}

Recebido para publicação em 31.3.2011 e aprovado em 15.10.2011.

2 Engo-Agrō-, M.Sc., Transferência de Tecnologia, Embrapa Florestas. Colombo, PR. Programa de Pós-graduação em Fitotecnia. Faculdade de Agronomia. UFRGS, Porto Alegre-RS. ${ }^{3}$ Professor Adjunto, Dep. de Plantas de Lavoura, Faculdade de Agronomia, Universidade Federal do Rio Grande do Sul - UFRGS, 91501-970 Porto Alegre-RS, Brasil, <merotto@ufrgs.br>; ${ }^{4}$ Professor, Instituto Federal do Rio Grande do Sul, Campus Sertão, Sertão, RS, Programa de Pós-Graduação em Fitotecnia. Faculdade de Agronomia, UFRGS, Porto Alegre-RS; ${ }^{5}$ Professora Associada, Dep. de Genética, Instituto de Biociências, UFRGS, Porto AlegreRS, Brasil.

Planta Daninha, Viçosa-MG v. 29, p. 1175-1181, 2011. Número Especial 
gene flow of resistance to herbicides and introgression of traits related to the adaptation between these plants. The M13 tailed primer method allowed the use of several micro-satellite molecular markers from a single fluorescent marker and made multiplex analyses possible. The increased availability and knowledge of molecular techniques can provide better results in several studies related to weed species with little availability of specific molecular markers.

Keywords: rd rice, M13-tail, hybridization, tiled primer, simple sequence repeats, SSR.

\section{INTRODUÇÃO}

Atualmente, diversos marcadores moleculares com características específicas estão disponiveis, e os mais modernos são inicialmente desenvolvidos para espécies-modelo ou de elevada importância econômica. Os marcadores simple sequence repeat (SSR) ou microssatélites são amplamente utilizados devido a alta disponibilidade, repetibilidade, polimorfismo e ao caráter codominante (Varshney et al., 2005). O desenvolvimento inicial de marcadores moleculares demanda grande quantidade de trabalho e recursos financeiros (Jones et al., 2009). Alternativamente, é possivel a utilização de marcadores originalmente desenvolvidos em determinada espécie para estudos em espécies similares (PalmaSilva et al., 2007; Barbará et al., 2007). Esta possibilidade aumenta a viabilidade de execução de estudos na área de plantas daninhas, onde em geral são realizados estudos em espécies para as quais não há informações genéticas e moleculares. Outra limitação para estudos relacionados a marcadores moleculares é a necessidade de utilização de vários oligonucleotídeos iniciadores (primers), o que contribui para a elevação do custo do estudo a ser realizado (Missiagglia \& Grattapaglia, 2006). Assim, a utilização de marcadores moleculares de outras espécies em conjunto com a otimização de procedimentos experimentais pode viabilizar o aumento da realização de estudos de biologia molecular, principalmente na área de plantas daninhas.

Os marcadores moleculares SSR são repetições variáveis em tandem de uma pequena região de um a seis pares de nucleotídeos repetidos muitas vezes (Jones et al., 2009). Devido à sua alta taxa de mutações, essas regiões são de grande interesse na genética de populações. As mutações resultam em marcadores altamente polimórficos, permitindo discriminação genética de indivíduos proximamente relacionados, mesmo empregando um número relativamente baixo de marcadores. Ainda, o caráter codominante dos marcadores SSR permite a distinção entre homozigotos e heterozigotos (Varshney et al., 2005). Já a presença de múltiplos alelos por locus favorece a avaliação da diversidade genética de populações e subpopulações mesmo em espécies com alto grau de autogamia (Zhang et al., 2009), como a maioria das plantas daninhas. A análise de marcadores microssatélites consiste em reações de PCR convencional, seguida pela verificação dos resultados em gel de agarose, poliacrilamida ou através de eletroforese capilar automatizada (Menksen \& Kahl, 2005). A análise em gel de agarose apresenta facilidade de execução, porém possui baixa capacidade discriminatória dos fragmentos. A análise em gel de poliacrilamida possui melhor precisão, porém apresenta maior dificuldade de execução e custos do que a análise em gel de agarose. Alternativamente, a identificação de fragmentos resultantes da amplificação em $\mathrm{PCR}$ pode ser realizada em equipamentos de eletroforese capilar também utilizados para sequenciamento de DNA (Gupta et al., 2010). Esse procedimento apresenta alta precisão, porém possui alto custo, que é relacionado ao equipamento e, principalmente, à necessidade de marcação dos oligonucleotídeos iniciadores com fluoróforos específicos (Missiagglia \& Grattapaglia, 2006).

A técnica da cauda fluorescente proposta por Oetting et al. (1995) consiste na marcação dos fragmentos de PCR com fluoróforos presentes em um iniciador universal. Nesta técnica, o iniciador forward a ser utilizado é sintetizado com a adição de sequência de um iniciador universal (por exemplo, M13), que corresponde à chamada cauda (Figura 1). Concomitantemente, um iniciador M13 é sintetizado com fluoróforo (por exemplo, 6-FAM). 


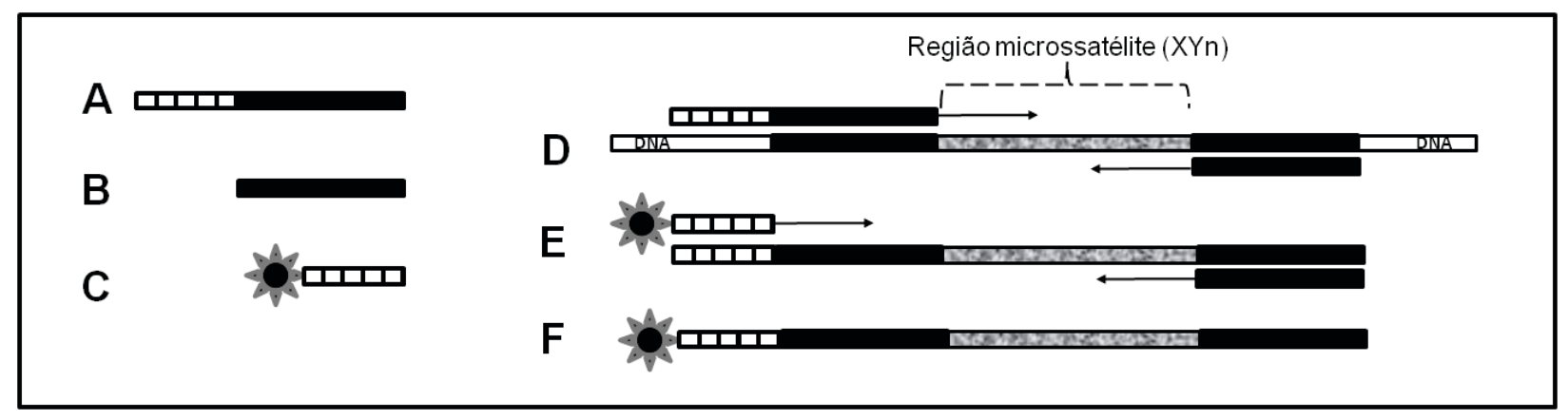

Figura 1 - Esquema ilustrativo dos oligonucleotídeos iniciadores e da amplificação de um marcador microssatélite pelo método da cauda M13 fluorescente. A) Iniciador forward contendo a cauda M13 na extremidade 5'. B) Iniciador reverse não alterado. C) Iniciador M13 marcado com o fluoróforo 6-FAM. D) Primeira etapa da PCR: o iniciador forward com a cauda M13 é incorporado ao DNA a ser amplificado. E) Segunda etapa da PCR: o iniciador M13 marcado com 6-FAM anela-se à cauda M13 dos fragmentos. F) Os fragmentos finais contêm o fluoróforo 6-FAM e podem ser analisados em eletroforese capilar automatizada. A região microssatélite marcada refere-se às sequências repetidas XY de um marcador hipotético. Adaptado de Oetting et al. (1995) e Schuelke (2000).

O iniciador reverse não é alterado em relação à sua utilização regular (Figura 1). Assim, a amplificação é realizada com três iniciadores: o forward contendo a sequência complementar ao M13 (cauda), o iniciador reverse e o iniciador M13 marcado com fluorescência (Figura 1). A PCR então ocorre em duas etapas (Schuelke, 2000). Na primeira, os fragmentos são amplificados de forma usual, a partir dos iniciadores forward e reverse. Estes fragmentos contêm a cauda M13 na extremidade forward (Figura 1). $\mathrm{Na}$ sequência, são incluídos ciclos adicionais de amplificação, com o objetivo de inserir o iniciador M13 marcado com 6-FAM nos fragmentos amplificados pelos ciclos anteriores (Schuelke, 2000). Dessa forma, os fragmentos podem ser visualizados tanto em gel de agarose quanto em eletroforese capilar automatizada. A principal vantagem da técnica da cauda fluorescente é que apenas o iniciador M13 requer marcação com fluoróforo, e este pode ser utilizado com vários oligonucleotídeos iniciadores distintos (Schuelke, 2000). Na ciência das plantas daninhas, sobretudo no Brasil, essa técnica é pouco difundida, embora tenha sido utilizada em estudos sobre animais e vegetais (Palma-Silva et al., 2007; Diniz et al., 2007; Banhos et al., 2008). Salienta-se que a análise de genotipagem a partir de oligonucleotídeos marcados em equipamentos de eletroforese capilar automatizada é realizada de forma terceirizada em vários laboratórios, o que facilita sua utilização e resulta em custos acessíveis.
O aumento da disponibilidade de marcadores moleculares em diversas espécies cultivadas e em espécies-modelo facilitará a utilização dessas ferramentas na área da ciência das plantas daninhas. Dessa forma, a associação da crescente disponibilidade de marcadores moleculares microssatélites, da técnica da cauda fluorescente e da facilidade de realização das análises resulta em ganhos relacionados à facilidade de execução e diminuição do custo operacional. O aumento da disponibilidade e do conhecimento de técnicas moleculares pode proporcionar a melhor elucidação em vários estudos relacionados à área da ciência das plantas daninhas. Como exemplo desses estudos, destacam-se a identificação de espécies, biótipos e cultivares, origem das invasões, dinâmica e estrutura populacional, identificação, fluxo gênico e evolução da resistência a herbicidas, bem como a associação e identificação de determinadas características das plantas daninhas através de QTLs (Quantitative Trait Loci). O objetivo deste trabalho foi descrever a técnica da cauda fluorescente como forma de otimização do uso de marcadores moleculares microssatélites, utilizando como exemplo um estudo de identificação de híbridos entre arrozvermelho e cultivado.

O material vegetal consistiu de plantas de arroz-vermelho (Oryza sativa), dos cultivares de arroz IRGA 417, IRGA 422 CL, PUITÁ INTA CL e Sator CL, e dos híbridos originados 
de cruzamento artificial entre esses cultivares de arroz e o arroz-vermelho. A extração de DNA de aproximadamente $150 \mathrm{mg}$ de material vegetal foi realizada através do protocolo adaptado de Haberer et al. (1996). Os marcadores microssatélites foram obtidos a partir de estudos de caracterização molecular e pureza varietal de arroz (Rangel et al., 2008; Sundaram et al., 2008), e as sequências dos oligonucleotídeos iniciadores foram obtidas na base de dados Gramene (http://www.gramene.org). Inicialmente, foram avaliados os marcadores 4797, RM106, RM180, RM234, RM251, RM253, RM341 e RM475 em relação à ocorrência de polimorfismo, através dos procedimentos convencionais utilizados para marcadores moleculares microssatélites. Os marcadores 4797, RM252, RM341 e RM475 apresentaram polimorfismo entre os genótipos avaliados. Os resultados obtidos com os marcadores 4797 e RM251 em relação à discriminação de híbridos de arroz-vermelho e o cultivar IRGA $422 \mathrm{CL}$ foram selecionados para discussão neste estudo. Posteriormente, cada um desses marcadores foi sintetizado de acordo com a técnica da cauda fluorescente, conforme descrito anteriormente. Esses marcadores foram sintetizados adicionando-se a cauda M13 de 18 pb de sequência 5' TGTAAAACGACGGCCAGT-3' na extremidade 5' do iniciador forward de cada marcador. Assim, as sequências foward e reverse do marcador 4797 são 5' TGTAAAAC GACGGCCAGTGGAGAAGGCAATGCAACACG-3' e 5' GCCATTGCCGCCAAGTACTA-3', respectivamente. As sequências foward e reverse do marcador RM341 são 5' TGTAAAACGACG GCCAGTCAAGAAACCTCAATCCGAGC-3' e 5' CTCCTCCCGATCCCAATC-3' respectivamente. As sequências sublinhadas correspondem ao iniciador M13. As temperaturas de anelamento dos iniciadores M13, 4797 e RM341 são de 53,60 e $56^{\circ} \mathrm{C}$, respectivamente. O iniciador M13 foi sintetizado com a adição do fluoróforo 6-FAM (6 carboxi fluorescina).

As amplificações foram realizadas em um volume total de $12 \mu \mathrm{L}$, contendo $25 \eta$ g de DNA, $0,2 \mu \mathrm{M}$ do iniciador forward com cauda M13, $0,8 \mu \mathrm{M}$ do iniciador reverse, $0,8 \mu \mathrm{M}$ do iniciador M13 marcado com 6-FAM, 0,150 $\mu$ M de cada deoxinucleotídeo trifosfato (dNTP), 0,5 U de Taq DNA polimerase, $1 \mathrm{x}$ buffer, e $0,6 \mathrm{mM}$ de $\mathrm{MgCl}_{2}$. As reações foram sujeitas a $5 \mathrm{~min}$ de desnaturação a $94{ }^{\circ} \mathrm{C}, 30$ ciclos de 45 s a $94{ }^{\circ} \mathrm{C}$,
45 s a 56 ou $60{ }^{\circ} \mathrm{C}$ para os iniciadores RM341 e 4797 , respectivamente, $1 \mathrm{~min}$ a $72^{\circ} \mathrm{C}$ e oito ciclos de 45 s a $94{ }^{\circ} \mathrm{C}, 45$ s a $53{ }^{\circ} \mathrm{C}, 1 \mathrm{~min}$ a $72{ }^{\circ} \mathrm{C}$ e $10 \mathrm{~min}$ a $72{ }^{\circ} \mathrm{C}$. As reações foram realizadas em termociclador PTC-100' ${ }^{\mathrm{TM}}$ (MJ Research).

Inicialmente, as amostras foram visualizadas em gel de agarose 3\%, contendo brometo de etídio com marcador de $100 \mathrm{pb}$ (Invitrogen), para confirmação das amplificações. Os géis foram fotografados com o programa KODAK Digital Science 1D. Posteriormente, a identificação dos fragmentos foi realizada em sequenciador automático ABI 3730 XL (Applied Biosystems) pela empresa Macrogen (Seul, Coreia do Sul). As reações dos quatro marcadores microssatélites foram organizadas em dois duplex, com base nos tamanhos de fragmento esperados. Os pares agrupados correspondem aos iniciadores 4707 e RM341, e RM251 e RM475. Assim, reduziu-se pela metade o custo da análise, pois, em vez de quatro injeções por amostra no sequenciador, foram necessárias apenas duas. Os resultados obtidos referem-se a uma planilha eletrônica contendo os alelos que correspondem aos tamanhos dos fragmentos e ao eletroferograma contendo os picos correspondentes aos alelos amplificados. Os resultados foram conferidos visualmente com base nos eletroferogramas, em comparação com as informações obtidas em gel de agarose.

Os resultados das amplificações obtidos em gel de agarose estão exemplificados na Figura 2. Os fragmentos apresentaram tamanho maior em relação ao tamanho referente aos marcadores originais devido à adição da cauda M13 incluída no iniciador forward. Ambos os marcadores mostraram polimorfismo entre o cultivar de arroz IRGA 422 CL e arrozvermelho, e a presença de duas bandas no híbrido é correspondente aos dois genótipos parentais (Figura 2). A Figura 3 ilustra os resultados da amplificação de fragmentos microssatélites com oligonucleotídeo iniciador marcado com $6 \mathrm{FAM}$, conforme o método da cauda M13 fluorescente. O tamanho dos picos observados está relacionado à intensidade da fluorescência, em que picos de 1.000 unidades (grandeza adimensional) são considerados adequados para detecção dos alelos de forma confiável e precisa (Figura 3). Por outro lado, a análise de picos menores depende da reação 
do padrão de amplificação. A amplificação com o marcador 4797 apresentou picos entre 400 e 600 unidades (Figura 3). No entanto, esses picos foram consistentes entre as análises realizadas; assim, assume-se que não são resultados de amplificações aleatórias. Ainda, o tamanho dos fragmentos obtidos nesses picos corresponde ao tamanho esperado para este marcador com base na informação referente ao seu desenvolvimento (Rangel et al., 2008), e também com relação aos resultados verificados no gel de agarose tanto no procedimento convencional de análise de microssatélites quanto no resultante da técnica de cauda fluorescente (Figura 2).

A análise dos fragmentos em sequenciador automático de DNA é mais precisa e expedita em comparação aos géis de agarose ou poliacrilamida (Gupta et al., 2010). Géis de agarose permitem que sejam detectadas variações em torno de 10 pares de base (Menksen \& Kahl, 2005). A precisão obtida com géis de poliacrilamida é maior que a obtida com agarose e muito próxima da obtida em eletroforese capilar (Menksen \& Kahl, 2005). No entanto, a análise em gel de poliacrilamida é mais trabalhosa do que a detecção em equipamento de eletroforese capilar. A presença do padrão ROX em cada reação da eletroforese capilar aumenta a precisão da análise em comparação ao padrão ladder utilizado em eletroforese em gel. Por isso, a análise de eletroforese capilar automatizada permite a detecção de alelos com apenas uma base de diferença com grande segurança e confiabilidade (David et al., 1993). Assim, o

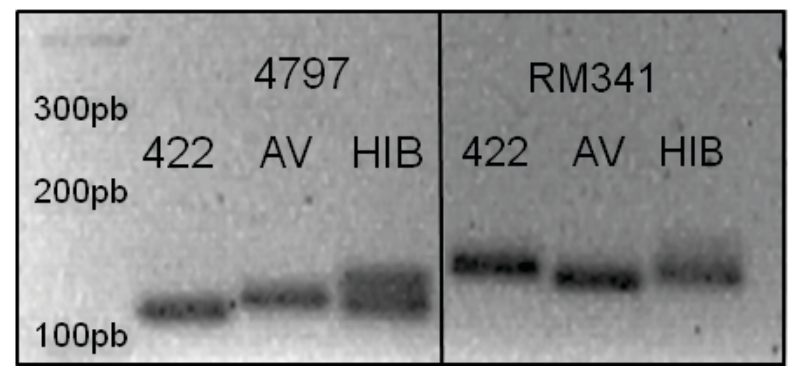

Figura 2 - Gel de agarose indicando os fragmentos resultantes da amplificação com os oligonucleotídeos iniciadores microssatélites RM251 e 4797 em arroz do cultivar IRGA 422 CL (422), arroz-vermelho (AV) e no híbrido oriundo do cruzamento artificial de IRGA 422CL e arrozvermelho (HIB). Coluna da esquerda corresponde a Ladder de $100 \mathrm{pb}$

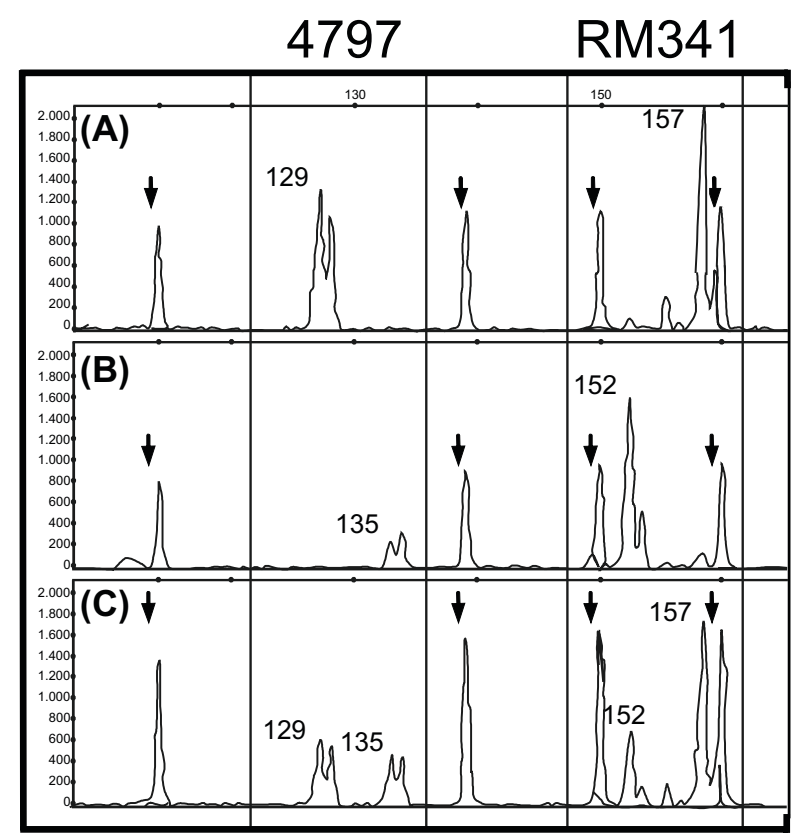

Figura 3 - Eletroferogramas dos oligonucleotídeos iniciadores 4797 (à esquerda) e RM341 (à direita) amplificados de arroz cultivado IRGA 422 CL (A), arroz-vermelho (B) e híbrido originado do cruzamento artificial de IRGA 422CL e arrozvermelho, obtidos mediante amplificação com a técnica da cauda M13 fluorescente. As setas indicam os picos correspondentes ao padrão ROX, e os números, o tamanho dos alelos observados em pares de base.

poder discriminatório de indivíduos é maior na eletroforese capilar automatizada, em comparação aos géis de agarose e poliacrilamida (Menksen \& Kahl, 2005; Gupta et al., 2010). Por exemplo, observa-se na Figura 3 que os alelos referentes aos indivíduos analisados diferiram em apenas $6 \mathrm{pb}$ e $5 \mathrm{pb}$ para os marcadores 4797 e RM341, respectivamente. Como a leitura do tamanho dos alelos no gel de agarose é realizada visualmente, alelos de tamanhos próximos podem ser equivocadamente considerados apenas um alelo (Figura 2). Entretanto, esses fragmentos foram detectados pela eletroforese capilar automatizada, resultando em clara diferenciação dos alelos (Figura 3).

Além da maior precisão, a análise de grande volume de dados através da eletroforese capilar automatizada é mais expedita e menos laboriosa em comparação com a análise em gel (David et al., 1993). Além das vantagens apresentadas, a técnica da cauda fluorescente permite que os marcadores sejam organizados 
em multiplexes de até seis marcadores em uma única PCR (Oetting et al., 1995; Hayden et al., 2008a). Ainda, alguns trabalhos apontaram a possibilidade de utilização dessa técnica com os marcadores SNP (Single Nucleotide Polymorphism), o que pode favorecer estudos com essa classe de marcadores moleculares (Hayden et al., 2008b).

A genotipagem de indivíduos através do método da cauda M 13 marcada com fluoróforo foi realizada em diversas espécies, como eucalipto (Missiaggia \& Grattapaglia, 2006), trigo e cevada (Hayden et al., 2008a) e milho (Hufford et al., 2011). Entretanto, qualquer que seja a finalidade do estudo envolvendo marcadores microssatélites, a técnica da cauda fluorescente pode potencialmente ser aplicada (David et al., 1993). Nesses trabalhos, os autores frisam o baixo custo como a principal vantagem desse método, conforme previsto por Schuelke (2000). Isso se refere à necessidade de marcação com fluoróforo apenas da sequência iniciadora M13. Por exemplo, no presente estudo, um único oligonucleotídeo iniciador marcado com fluoróforo permitiu a análise através de eletroforese capilar com quatro marcadores moleculares. De outra forma, todas as sequências iniciadoras forward deveriam ser marcadas. A incorporação do fluoróforo aumenta o custo da sintese em aproximadamente $500 \%$, em relação ao custo da sintese de um iniciador não marcado. Por sua vez, a inclusão da cauda M13 no oligonucleotídeo iniciador aumenta seu custo em $100 \%$. A técnica da cauda M13 resulta em economia porque uma única marcação com fluoróforo permite a utilização de vários oligonucleotídeos iniciadores (Missiaggia \& Grattapaglia, 2006). Além disso, o tempo necessário para realização das análises no equipamento de eletroforese capilar automatizada é menor em comparação com o de outros métodos. A análise em gel de poliacrilamida demanda dois dias de preparação para avaliação de 96 amostras, ao passo que sequenciadores automáticos realizam esse trabalho em aproximadamente 50 minutos. Além disso, a possibilidade de organização de marcadores em multiplex na amplificação em PCR ou somente na identificação dos resultados também proporciona vantagens operacionais e de custo. Na Figura 3 é apresentada a análise dos marcadores 4797 e RM 341 realizada de forma conjunta em biplex, resultando na otimização da análise de eletroforese capilar.

Os resultados apresentados demonstram a capacidade de marcadores microssatélites empregados com a técnica da cauda fluorescente de identificação de híbridos de arrozvermelho e cultivado, cuja utilização pode ocorrer em estudos relacionados, por exemplo, à determinação de fluxo gênico da resistência a herbicidas, ou à introgressão de características agronômicas ou silvestres entre essas plantas. O método da cauda fluorescente associado à detecção automática de alelos é simples e relativamente rápido em comparação com métodos convencionais de gel de agarose ou poliacrilamida. Ele é também mais barato em relação à forma convencional de análise automática com marcadores individuais marcados com fluoróforos. Essas características aumentaram a viabilidade da realização de estudos com marcadores moleculares, sobretudo na área de plantas daninhas, em que se objetiva avaliar um grande número de espécies para as quais existe pouca disponibilidade de marcadores moleculares específicos.

\section{LITERATURA CITADA}

BANHOS, A. et al. Genomic resources for the conservation and management of the harpy eagle (Harpia harpyja, Falconiformes). Genet. Molec. Biol., v. 31, n. 1, p. 146-154, 2008.

BARBARÁ, T. et al. Cross-species transfer of nuclear microsatellite markers: potential and limitations. Molec. Ecol., v. 16, n. 18, p. 3759-3767, 2007.

DAVID, L. S.; SCOTT, L. S.; STEPHEN, C. R. An alternate universal forward primer for improved automated DNA sequencing of M13. BioTechniques, v. 15, n. 4, p. 580-582, 1993.

DINIZ, F. M. et al. Application of a double-enrichment procedure for microsatellite isolation and the use of tailed primers for high throughput genotyping. Genet. Molec. Biol., v. 30, n. 2, p. 380-384, 2007.

GUPTA, V., et al. Gel versus capillary electrophoresis genotyping for categorizing treatment outcomes in two antimalarial trials in Uganda. Malaria J., v. 9, n. 1, p. 19, 2010.

HAYDEN, M. et al. Application of multiplex-ready PCR for fluorescence-based SSR genotyping in barley and wheat.

Molec. Breed., v. 21, n. 3, p. 271-281, 2008 a. 
HAYDEN, M. et al. Multiplex-Ready PCR: A new method for multiplexed SSR and SNP genotyping. BMC Genomics, v. 9, n. 1, p. 80,2008 b.

HABERER, G.; FISCHER, T. C.; TORRESRUIZ, R. A. Mapping of the nucleolus organizer region on chromosome 4 in Arabidopsis thaliana. Molec. Gen. Genet., v. 250, n. 1, p. 123-128, 1996.

HUFFORD, M. B., GEPTS, P.; ROSS-IBARRA, J. Influence of cryptic population structure on observed mating patterns in the wild progenitor of maize (Zea mays ssp parviglumis). Mol. Ecol., v. 20, n. 1, p. 46-55, 2011.

JONES, N. et al. Markers and mapping revisited: finding your gene. New Phytol., v. 183, n. 4, p. 935-966, 2009.

MENKSEN, K.; KAHL, G. Handbook of plant genome mapping. Weinheim: Wiley, 2005. v. 1. 403 p.

MISSIAGGIA, A.; GRATTAPAGLIA, D. Plant microsatellite genotyping with 4-color fluorescent detection using multipletailed primers. Genet. Molec. Res., v. 5, n. 1, p. 72-78, 2006.

OETTING, W. S. et al. Linkage analysis with multiplexed short tandem repeat polymorphisms using infrared fluorescence and m13 tailed primers. Genomics, v. 30, n. 3, p. 450-458, 1995.
PALMA-SILVA, C . et al. A set of polymorphic microsatellite loci for Vriesea gigantea and Alcantarea imperialis (Bromeliaceae) and cross-amplification in other bromeliad species. Molec. Ecol. Notes, v. 7, n. 4, p. 654-657, 2007.

RANGEL, P. N. et al. Agronomic and molecular characterization of introgression lines from the interspecific cross Oryza sativa (BG90-2) x Oryza glumaepatula (RS-16). Genet. Molec. Res., v. 7, n. 1, p. 184-195, 2008.

SCHUELKE, M. An economic method for the fluorescent labeling of PCR fragments. Nat. Biotechnol., v. 18, n. 2, p. 233-234, 2000.

SUNDARAM, R. et al. Identification of informative SSR markers capable of distinguishing hybrid rice parental lines and their utilization in seed purity assessment. Euphytica, v. 163 , n. 2 , p. $215-224,2008$.

VARSHNEY, R. K.; GRANER, A.; SORRELLS, M. E. Genic microsatellite markers in plants: features and applications. Trends Biotechnol., v. 23, n. 1, p. 48-55, 2005.

ZHANG, D. et al. Genetic structure and differentiation of Oryza sativa L. in China revealed by microsatellites. Theor. Appl. Genet., v. 119, n. 6, p. 1105-1117, 2009. 